\title{
Review of materials used for ballast reinforcement
}

\author{
M. Ahmad* \\ Széchenyi István University, Structural and Geotechnical Engineering \\ Department, Egyetem tér 1, 9026 Győr, Hungary \\ *e-mail: ahmad.majd@hallgato.sze.hu
}

Submitted: 13/04/2021; Accepted: 29/04/2021; Published online: 14/05/2021

Abstract: This mini review summarizes the most recent research in ballast reinforcement. Several materials are being used for the purpose of improving the ballast layer in railways, including geosynthetics, rubber sheets and binding agents. Such methods of reinforcement have proven to be beneficial for increasing the strength, stiffness, and resilience of the ballast layer in addition to reducing settlement, breakage, degradation, and maintenance cost and frequency. Latest studies try to find the best types, placement, and combination of geosynthetics to achieve the highest strength and resistance, in addition to obtaining the optimum percentage of binding agents and methods of applying them in order to discover the most effective binder that achieves the most improvement to the mechanical properties of the layer for a reasonable price. An overview of the recent tests conducted to study the reinforced ballast layer and their results is presented in this paper, as well as an overall evaluation of the implementation of these reinforcement methods in railways.

Keywords: ballast reinforcement; geosynthetics, polyurethane, binding agents

\section{Introduction}

The ballast layer plays an important role as a foundation of the railway tracks. It is vital to ensure the quality of the ballast in order to transmit the loads applied on the superstructure to the substructure safely while maintaining adequate longitudinal and cross-direction stability to the railway track. Granular materials with high strength and inner friction are used for this layer to allow fast seepage of 
precipitation and low permanent deformations. Many problems may develop in the ballast due to the static and cyclic loading conditions imposed by the trains, including large settlements which cause speed restrictions and compromise the passengers' comfort. Ballast fouling is also a common issue, when the finer material mixes with the fresh ballast, altering the particle size distribution, settlements, and permeability characteristics of the ballast. This phenomenon might be due to the crushing of the top granular material or when finer particles infiltrate the ballast from underlaying layers. Excessive deformations can also be caused by substructure failures which lead to very costly maintenance procedures [1].

Poorly constructed ballast will lead to excessive deformations and differential settlements in the railway track, causing concerns about the safety of the passengers. Quick and usually costly measures should be taken regularly in that case to maintain the good functional quality of the railway and to ensure not to exceed the serviceability limit state. In order to reduce the maintenance costs and frequency, several methods were introduced to reinforce the ballast layer with the aim of increasing the shear strength, stiffness, lateral resistance, and resilient modulus and decrease deformation, degradation and breakage of the ballast.

The most common methods used for ballast reinforcement are geosynthetics (e.g., geogrid, geonet and geotextile), Polyurethane, rubber energy absorbing drainage sheets, and binding agents such as bitumen, organosilane and lignosulphonate. A variety of field and laboratory tests are conducted recently to assess the performance of these improvement methods. The most used tests include direct shear test, plate load test, drop hammer impact test, repeated load triaxial tests, single tie push test and track panel displacement test. An overview of the recent research conducted to evaluate the efficiency of the improvement methods of ballast is presented in this paper, and an overall comparison between the methods is introduced.

\section{Ballast reinforcement methods}

\subsection{Geosynthetics}

Geosynthetic is defined as "a planar product manufactured from a polymeric material that is used with soil, rock, or other geotechnical-related material as an integral part of a civil engineering project, structure, or system" [2]. It has several application depending on its type and shape including reinforcement, filtration, and separation. 3 main types of geosynthetics are used for ballast improvement:

- Geotextiles consist of synthetic flexible and porous fabrics characterized by a relatively high percentage open area (6-30\%), mainly used in the 
ballast for separation to reduce the amount of fouling leading to a reduction in settlement and maintenance cost.

- Geonets are created by a continuous extrusion of parallel sets of polymeric ribs at acute angle to one another, mainly used for their inplane drainage capabilities and usually used along with another type of geosynthetics for reinforcement and drainage improvement.

- Geogrids are plastics formed into a very open, grid-like configuration, the openings between the adjacent longitudinal and transverse ribs are large enough to allow for soil communication. they function almost exclusively as reinforcement materials due to its high strength, high modulus, and low creep. The usage of geogrids to stabilize the ballast layer has proven to be effective by increasing its shear strength, lateral resistance and vertical stiffness and decreasing breakage, deformation, and degradation.

\subsection{Polyurethane}

Polyurethane is made by chemical reaction of isocyanate compound with hydroxy compound. It can be found in different forms, including rigid foams, flexible foams, chemical-resistant coatings, and elastomers. The two most common polyurethane used for ballast improvement are XiTRACK and Elastan, which are unfoamed material, performing stiff bonding. XiTRACK has a much lower gel-time (10 secons) than Elastan (30-60 minutes) and reaches $90 \%$ of its strength in a shorter time (one hour) than Elastan (72 hours).

The two components of the polyurethane are mixed in situ through mixing equipment and poured, sprayed, or injected in the track. When it flows through the voids of the ballast particles, a gel-like material is created around the particles, generating a strong ballast-polyurethane matrix that is hard to break even at temperatures up to $230^{\circ}$. The voids of the ballast are partially filled with the polyurethane; therefore, it maintains both permeability and the ballast track's capacity to support train loads.

A new more economical type of polyurethane was introduced in Korea called ERSBallast, it has properties that are similar to XiTRACK. However, it uses a different method when applied to the ballast layer, where it is designed to be injected based on the pressure distribution applied by train and transmitted to the ballast, reducing the amount needed by injecting only to regions where train loads are directly applied [3]. Recent research shows improvement in the ballast's shear strength, stiffness and friction when treated with polyurethane. 


\subsection{Binding agents}

The use of different types of binding agents in the ballast layer was found useful to increase its strength and improve drainage in addition to reducing permanent deformations and maintenance cost and frequency. For example, bituminous emulsion can be applied by spraying onto the ballast layer along the track to form what is called Bitumen Stabilised Ballast (BSB). Furthermore, a nanoscale agent called Organosilane which is not affected by change of temperature and ultraviolet radiation, showed positive results for improving the ballast because its components help forming an impervious nanolayer of alkyl siloxanes on the particles' surface.

Lignosulfonate can also be applied to the ballast (Lignosulfonate Stabilised Ballast LSB). It is an organic water-soluble material gained in papermaking industries. The recent research related to the use of lignosulfonate to improve the properties of coarse crushed rocks similar to the material used for ballast has shown promising results.

\subsection{Rubber mats}

Rubber mats were first used in railway to decrease noise and vibration. Subsequently they were used between the rail foundation and the ballast layer for better load distribution leading to a reduction in permanent deformations and improving stability. T.N. Ngo et al. [4] studied the influence of rubber energy absorbing drainage sheets (READS) in decreasing breakage, degradation, and deformation of the ballast layer by placing recycled rubber mats underneath the ballast layer and conducting large-scale impact tests. It can also be used in combination with different types of geosynthetics, especially geogrids.

\section{Field and laboratory tests for ballast evaluation}

\subsection{Single tie push test (STPT)}

This test is used to measure the lateral resistance of the railway track, where a hydraulic jack is connected to the outer surface of the rail where the lateral forces are applied, and a linear variable displacement transducer (LVDT) is installed on the outer surface of the other rail to measure the outer displacement (Fig. 1). The test can be conducted in the field on real constructed railway tracks, or smaller models can be created in the laboratory to simulate the same conditions of the field on a smaller scale with a vertically loaded or unloaded tie. 


\subsection{Direct shear test}

This test is used to find the shear strength of the specimen, by applying a predetermined normal stress followed by a shearing deformation with a constant rate while measuring the lateral displacement and the shearing force in the meantime. The test is described in (ASTM D3080). For ballast testing, a large-scale direct shear test machine that consists of two square boxes is used, with adequate dimensions to marginalize the impact of boundary conditions on the outcomes. The ballast is placed in the boxes in layers, and the geogrid is positioned on the interface of upper and lower boxes in case of testing the effect of geogrid on the shear resistance, or the ballast can be treated with the tested binding agent before placement to evaluate its shear strength. The friction angle can be calculated from the relationship between normal stress and shear stress at failure which is used to evaluate the shear strength of the specimen. Furthermore, breakage of the ballast due to shearing can be measured by retrieving the specimen from the shear box after the test and sieving it to assess the changes in ballast gradation. Marsal's Breakage index (Bg) is usually used which is the total sum of the positive values of $\Delta \mathrm{W}_{\mathrm{k}}$ in percentage, where positive $\Delta \mathrm{W}_{\mathrm{k}}$ is the reduction in percentage retained in each sieve.

\subsection{Process simulation test}

Large scale process simulation tests (PST) are used to simulate a track segment consisting of a sleeper beneath the rails that contribute to transmitting the applied loads to the ballast. In this test, the transverse and longitudinal movement of the track are simulated by the in and out movement of the walls of the PST apparatus. Five movable plates are placed in the middle of the shorter side walls to measure the lateral movement of the ballast along its depth. A set of five servo-controlled actuators are installed on each side of the walls to apply the lateral loads, and a vertical dynamic actuator is installed to apply a vertical pressure with a frequency up to $50 \mathrm{~Hz}$. The deformations are measured, and the resilient modulus is calculated for different frequencies.

\subsection{Plate load test}

This test is performed on the ballast material to find its stiffness and vertical loadsettlement curve, where ballast materials are compacted in several layers in a big chamber placed under a steel solid frame to withstand the reaction loads, which is fastened firmly to a robust huge base or foundation. The vertical stress is applied in phases through a hydraulic jack. Two important strain moduli are calculated as an assessment of the mechanical properties of the aggregates forming the ballast layer. $\mathrm{E}_{\mathrm{V} 1}$ is a short-term property obtained from the first cycle of loading, which is related 
to the in-situ density of the ballast. and $\mathrm{E}_{\mathrm{V} 2}$ is calculated from the second cycle, and it is more concerned with the mid to long-term characteristics.

\subsection{Los Angeles abrasion test (LAA)}

LAA test defined in (AASHTO T 96) or (ASTM C 131) is used to test durability and strength properties of ballast, by measuring the mass loss rate (LAA loss \%). The sample is placed in a rotating steel drum with a speed of 31 33 r/min along with steel balls. "After being subjected to the rotating drum, the weight of aggregate that is retained on a No. $12(1.70 \mathrm{~mm})$ sieve is subtracted from the original weight to obtain a percentage of the total aggregate weight that has broken down and passed through the No. 12 sieve. Therefore, an L.A. abrasion loss value of 40 indicates that $40 \%$ of the original sample passed through the No. 12 sieve" (AASHTO T 96).

\subsection{Triaxial test}

Normal and large scale triaxial tests are conducted to measure the stiffness and deformation resistance of the aggregates. The specimen is subjected to a uniform confining stress through pressurised water, in addition to a vertical static or dynamic stress (deviatoric stress) by using a hydraulic jack, with a maximum stress that adequately simulates the train loads. The resilience modulus is then calculated which is the ratio between the variation in the dynamic vertical stress and vertical strain.

\subsection{Drop hammer impact test}

Drop weight impact tests are conducted to assess the capability of the reinforcement material to mitigate dynamic impact loads and reduce the degradation of the ballast. The device consists of a hammer allowed to free fall using rollers which are guided through low-friction runners on vertical steel columns fixed onto a reinforced concrete floor. The thickness of the ballast layer and the capping are determined to simulate the conditions in the field. The acceleration is measured through an accelerometer installed at the top surface of the sample, and the impact loads during the tests can be recorded by a dynamic load cell attached to the hammer, and the deformations are recorded by using a highspeed camera.

The vertical displacement, lateral deformations and ballast breakage are measured to evaluate the performance of the ballast and the reinforcement method under the dynamic impact loads.

A different and more up to date and unique laboratory test to measure ballast breakage was also introduced by Juhász and Fischer [5]. 


\section{Results}

The placement of the geogrid layer plays an important role for achieving a maximum effectiveness. F. Horvát et al. [6] conducted multi-level shear box tests on granular aggregate that is used as a railway ballast layer to study the inner shear resistance with and without compaction, and the effect of reinforcement with 2 types of geogrid combined in some cases with geotextile (geocomposite). The inner shear resistance was increased after the reinforcement. However, it was found that the maximum shear strength was not at the geogrid-ballast interface, but $0-10 \mathrm{~cm}$ above the interface. Furthermore, geogrid with glued geotextile decreased the inner shear resistance because it obstructs the interlocking between the aggregates and the geocomposite.

M. Esmaeili et al. [7] studied the effect of geogrid reinforcement on ballasted track's lateral resistance by conducting field and laboratory STPT to evaluate its performance with different number of geogrid layers in the ballast. In the lab, they used a $4 \times 1 \mathrm{~m}$ geogrid sheets on different levels of a $(30,40$ and $50 \mathrm{~cm})$ thick ballast and under the central of 5 concrete ties (type B70), which was chosen for receiving the loads. The test was conducted on a vertically unloaded tie, and the jack applies a rate of $0.5 \mathrm{~mm}$ lateral displacement on the outer surface of the rail until it reaches $2 \mathrm{~mm}$. Their laboratory tests showed an increase in the lateral resistance of $31 \%$ for one layer of geogrid in a $30 \mathrm{~cm}$ thick ballast. This improvement diminished with the increase in the thickness of the ballast to $15 \%$ for a thickness of $40 \mathrm{~cm}$ and to $13 \%$ for $50 \mathrm{~cm}$. A further improvement was noticed when using two layers of geogrid, as the lateral resistance grew by $42 \%$ for a $30 \mathrm{~cm}$ thick ballast when compared to nonreinforced ballast. Similar behavior was noticed as before when increasing the thickness of the ballast layer, and the effect of the geogrid declined with the installation distance from the sleeper as can be seen in Fig. 2.

In the field, a part of a preconstructed railway track was removed to install two layers of geogrid in a $30 \mathrm{~cm}$ thick ballast supporting B70 concrete ties and two UIC60 rails. A robust wall was used to support the hydraulic jack. The filed findings showed very good compatibility with the laboratory results with a maximum of only $0.39 \mathrm{KN}$ difference in lateral force (5.6\% of the total force), and similarly, a $42 \%$ increase in lateral resistance was achieved with 2 layers of geogrid and $34 \%$ for a single layer. 
M. Ahmad - Acta Technica Jaurinensis, Vol. 14, No. 3, pp. 315-338, 2021

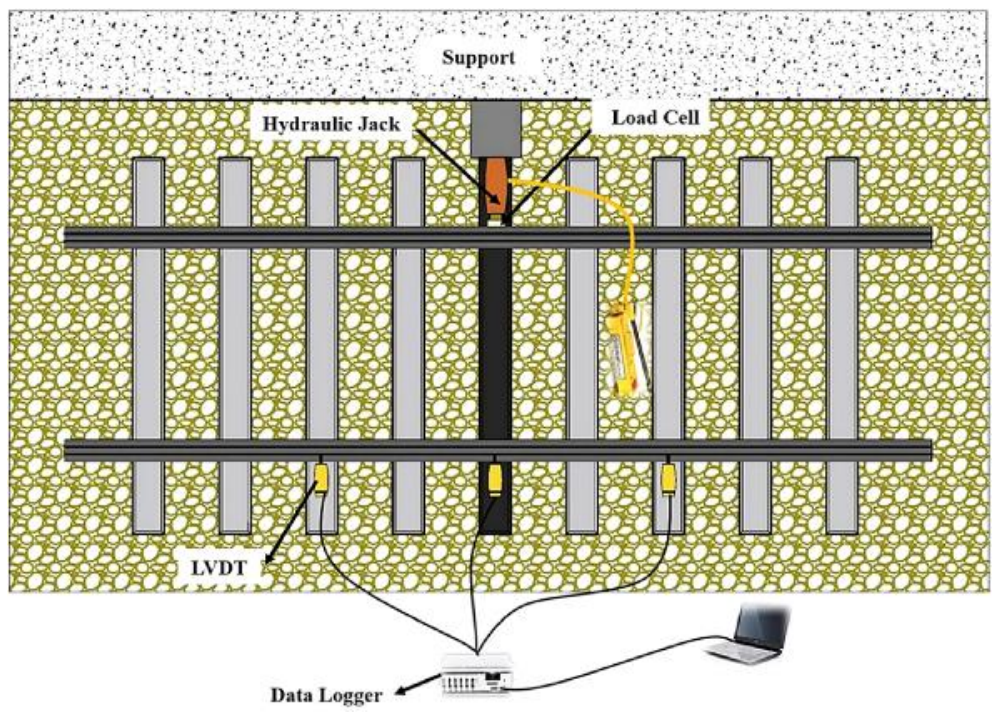

Figure 1. Illustration of the STPT test [7]

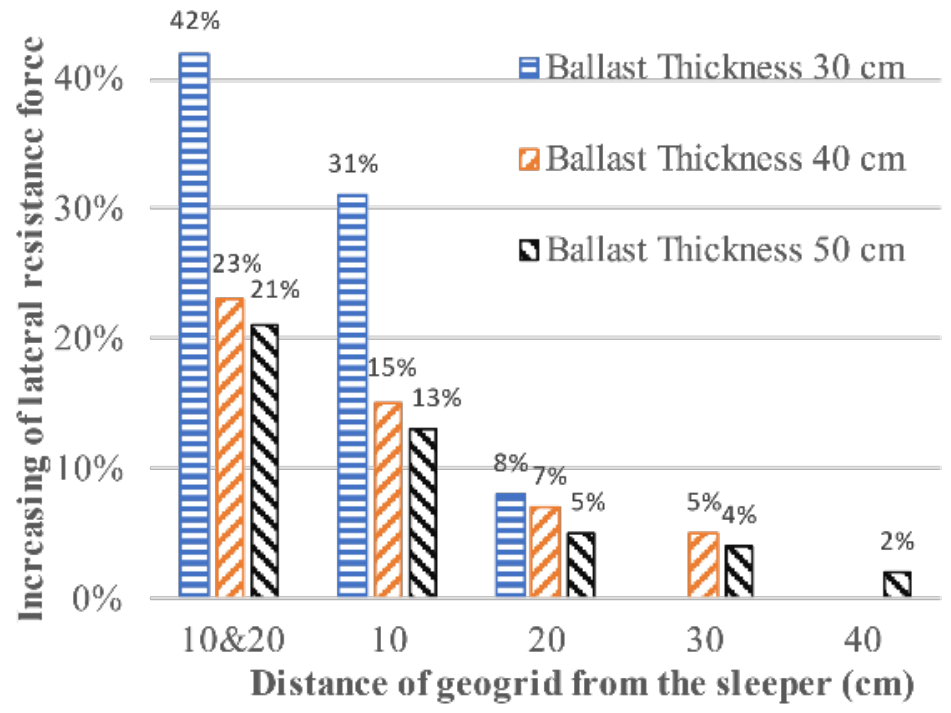

Figure 2. the increase in lateral resistance in STPT [7] 
Sweta and Hussaini [8] performed large scale direct shear tests on fresh granite to study the influence of different types of geogrid on the shear strength of the ballastsubballast interface. The used apparatus consists of two 450x450 mm square boxes with a depth of $300 \mathrm{~mm}$, the lower box is fixed, and the upper box moves laterally to apply the shear forces. The subballast was compacted and placed in two layers in the lower box and the ballast was placed by the same means of compaction in the upper box after the geogrid was placed at the interface of the two layers. Loads were applied in magnitudes and rates that represent the real field conditions for a typical track with low confinement. The tests show a significant increase in the friction angle after reinforcement. However, this increase depends on the vertical stress and the shearing rate. The angle of friction could be increased to a maximum of $67.96^{\circ}$ when using PP (blaxial) geogrid (G1) with square aperture shape, and ultimate tensile strength of $30 \mathrm{KN} / \mathrm{m}$, compared to $63.42^{\circ}$ for unreinforced interface. They also found that the change in the angle of friction is given by a logarithmic equation which is a function of the rate of shear $\left(S_{r}\right)$ and the vertical stress $\left(\sigma_{n}\right)$ :

$$
\begin{aligned}
& \delta=-\mathrm{a}_{1} \ln \left(\sigma_{\mathrm{n}}\right)+\mathrm{a}_{2}, \\
& \delta=-\mathrm{b}_{1} \ln \left(\mathrm{S}_{\mathrm{r}}\right)+\mathrm{b}_{2},
\end{aligned}
$$

The equations show that apparent friction angle of ballast-geogrid-subballast interface $(\delta)$ declines with the increasing vertical stress and rate of shear stress, as the interface efficiency factor $\alpha$ which is the ratio $\tan (\delta) / \tan (\varnothing)$ drops from 1.22 to 1.15 as $S_{r}$ rises from 2.5 to $10.0 \mathrm{~mm} / \mathrm{min}$.

The ballast was retrieved from the shear box after each test and sieved in order to study the breakage of the ballast during shearing. According to their observation, "the breakage of ballast $\left(\mathrm{B}_{\mathrm{g}}\right)$ increases with the increase in $\sigma_{\mathrm{n}}$ and $\mathrm{S}_{\mathrm{r}}$ for both unreinforced and reinforced conditions" [8]. However, using the previously mentioned type of geogrid at the ballast-subballast interface reduced the breakage from 3.88 to $3.10 \%$.

In a later study, Sweta and Hussaini [9] used the same type of ballast and geogrid as their previous study to conduct process simulation tests (PST), this time to study the effect of geogrid on deformation response and resilient modulus of railroad ballast under cyclic loading. The apparatus box is 950x650 mm with a depth of 730 $\mathrm{mm}$, the loads are transferred from the rail to one sleeper of 950x250 mm, and the walls move in a way that simulates the real field conditions as can be seen in Fig. 3. The strains were measured in the transverse direction to find the lateral spreading of the ballast. The subballast was compacted in the box in two layers of $75 \mathrm{~mm}$ and a geogrid layer of reinforcement was installed, then the ballast was compacted in three layers of $127 \mathrm{~mm}$ to achieve the field density. The test specimen was loaded up to 250,000 cycles and at loading frequencies between 10 and $40 \mathrm{~Hz}$. Their results show 
a significant reduction in lateral displacement at the level of the geogrid (G1) of 59\% for a loading frequency of $10 \mathrm{~Hz}$. This enhancement was reduced to $49 \%$ for a frequency of $20 \mathrm{~Hz}$. On the other hand, the vertical displacement was decreased by $43 \%$ and $35 \%$ for frequencies of 10 and $20 \mathrm{~Hz}$, respectively. Nevertheless, the reduction in lateral and vertical deformation decreases substantially with the increase in vertical distance from the ballast-geogrid-subballast interface until it diminishes entirely at a certain distance (close to the sleeper). Moreover, the resilient modulus given by:

$$
\mathrm{M}_{\mathrm{r}}=\frac{\sigma_{\mathrm{cyc}}}{\epsilon_{\mathrm{r}}}
$$

Where " $\sigma_{c y c}$ is the cyclic deviator stress, $\epsilon_{r}$ is the recoverable axial strain during cyclic triaxial unloading” [9]. It was noticed that reinforcing with geogrid improves the resilient modulus of the ballast considerably, as it has increased by $25.8 \%$ and $21.4 \%$ for frequencies of 10 and $20 \mathrm{~Hz}$ respectively due to the increase in the effective confining pressure of the ballast. Fig. 4 shows the benefit of using the geogrid in improving the resilient modulus and the breakage of the ballast and the effect of the increasing frequency.

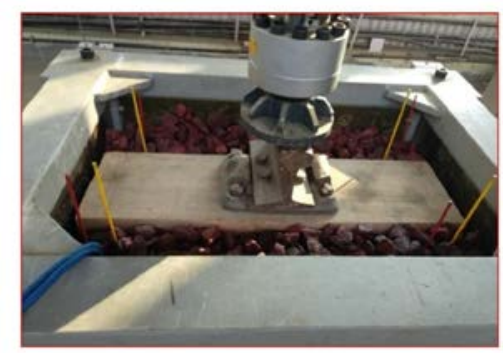

Figure 3. Illustration of the PST test [9]

Ballast contamination is a common problem that causes a change in the properties of this layer. J. Sadeghi et al. [10] addressed the issue of ballast contamination with sand and studied the effect of ballast layer reinforcement with geogrid to improve the mechanical properties of this layer. large-scale direct shear tests were done on dolomite limestone aggregates that comprise the ballast layer with several degrees of sand contamination. The degree of contamination as a percentage was defined as the ratio of the dry weight of contaminant particles with size less than $9.5 \mathrm{~mm}$ to the total dry weight of the sample. For the large-scale direct shear tests, the ballast was poured and compacted in two layers for each of the two boxes, and the sand was spread on each of the layers with different percentages to simulate the contamination conditions in real railway tracks. Three different types of geogrid with square 
aperture (24, 34 and $46 \mathrm{~cm}$ width) were placed on distances of $10 \mathrm{~cm}$ and $20 \mathrm{~cm}$ from the bottom. Their results shown in Fig. 5 indicate that the angle of friction decreases with the increasing contamination percentage regardless of the reinforcement. The angle of friction could be improved by up to $13 \%$ for clean ballast when using $34 \times 34$ geogrid installed $10 \mathrm{~cm}$ above the bottom of the ballast. The same type of geogrid with the same placement caused an enhancement in the ballast's shear strength by $25 \%$ as a result of the particle-grid interlocking. However, this enhancement declines considerably when the contamination level with sand increases due to the friction and contact loss between the aggregate particles, and the slip and slide of the particles on the geogrid.

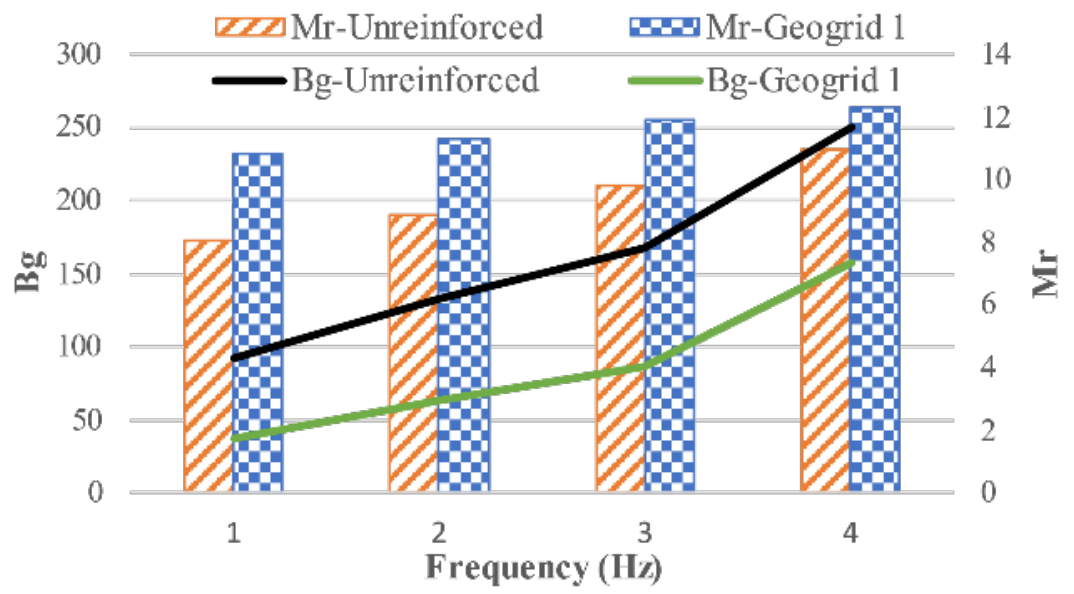

Figure 4. The effect of frequency and reinforcement on the resilient modulus $\left(M_{r}\right)$ and breakage $\left(B_{g}\right)$ of the ballast [9]

Javad Sadeghi et al. [10] also examined the same conditions as before by using the plate load test to find the vertical load-settlement curve of reinforced sand contaminated ballast. The test was conducted in a $(120 \times 120 \mathrm{~cm} 2)$ chamber with a depth of $100 \mathrm{~cm}$. The ballast was compacted in 3 layers of $10 \mathrm{~cm}$ each and two cycles of loading were applied. It was observed that the vertical settlement increased with the increasing percentage of contamination. However, the inclusion of the $34 \times 34$ geogrids $10 \mathrm{~cm}$ from the bottom caused a 30\% decrease in the settlement. Fig. 6 shows how the strain modulus for the second cycle (EV2) decreases with the increase in contamination. Furthermore, the increase in stiffness is noticed for different types of geogrids and their distances from the bottom. It can be also seen that when the contamination level exceeds $24 \%$ it is highly less effective to use geogrid and in that case cleaning of the ballast is necessary. 
M. Ahmad - Acta Technica Jaurinensis, Vol. 14, No. 3, pp. 315-338, 2021

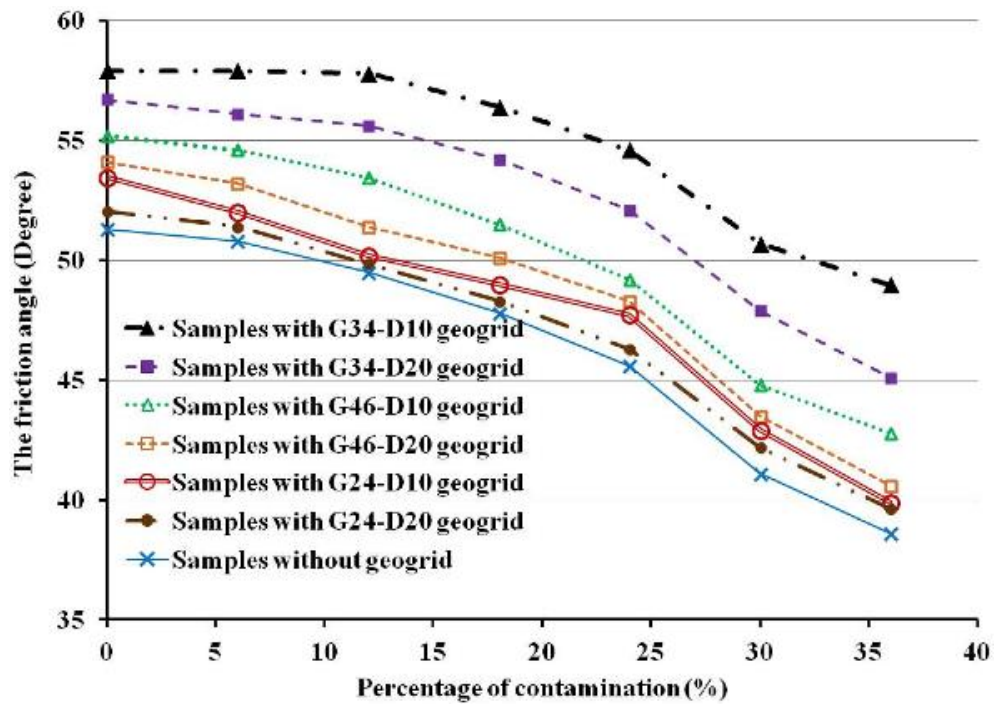

Figure 5. Change in friction angle of ballast samples with the increasing degree of contamination [10]

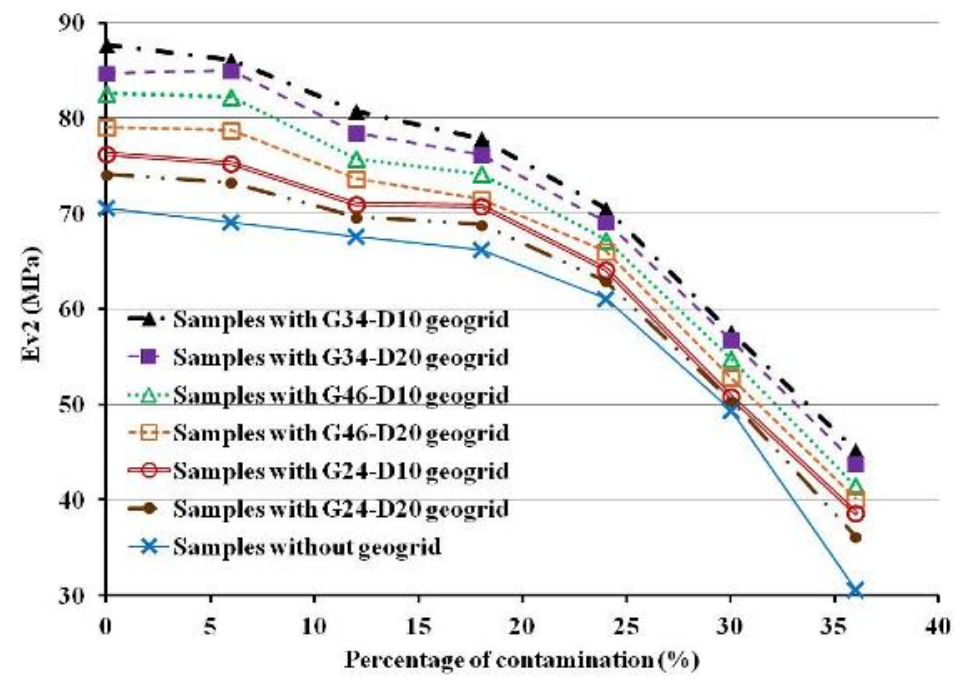

Figure 6. Change in the strain modulus of ballast samples with the increasing percentage of sand contamination in the second cycle of loading [10] 
Raghvendra Pratap Singh et al. [11] explored the effect of woven geotextile on the stability of the track by placing them at the ballast-subgrade interface and analyzing the degradation and fouling of the ballast. For this purpose, 173 ballast samples were collected from different locations of the single-track section (DN), and double-track section (UP) between Bhusawal and Akola in the state of Maharashtra, India, where about 20 trains pass per day of 20.5 tons for UP track (coal loaded trains), and 5.8 tons for the DN track (empty trains). The collected samples (with and without geotextile) were tested in the laboratory to assess ballast fouling, degradation and change in Los Angeles abrasion loss.

The fouling index is calculated from the particle size distribution curve as follows:

$$
\mathrm{FI}=\mathrm{P}_{4.75}+\mathrm{P}_{0.075},
$$

For the UP track, including the woven geotextile decreased the ballast fouling by $74 \%$ and $64 \%$ for parts of the track with 239 million load cycles (MGT) and 327 MGT respectively. However, fouling was reduced by about 28\% for the down track after the passage of 434 MGT traffic (11 years). Furthermore, installing woven geotextile decreased the breakage index $(\mathrm{Bg})$ by $17 \%$ on both tracks. They also found that for tracks reinforced with geotextile at the ballast-subgrade interface, "the deep screening cycles could be increased by 5 years on DN track and by 200 MGT traffic on UP track” [11].

The optimum content of additives that strengthens the ballast layer is an intruiging topic for multiple researchers. S. H. Lee et al. [3] conducted large-scale triaxial tests to examine the properties of ballast mixed with polyurethane with different mixing ratios. Ballast only samples were compacted in a $300 \mathrm{~mm}$ diameter and $620 \mathrm{~mm}$ height steel mold and confined before applying the axial loading since it cannot be self-supported. On the other hand, for the polyurethane-mixed ballast samples, the polyurethane was poured on previously compacted ballast in an acrylic cylinder and was left to cure. The tests were conducted on specimens with $(70,140$, and $210 \mathrm{~kg} / \mathrm{m}^{3}$ ) polyurethane contents in unicaxial conditions, which is more similar to the field conditions. The polyurethane-mixed ballast showed two linear regions seperated with two drops in the stress-strain curve with a lower stiffness for the first line which is more governed by the ballast than the polyurethane. The two regions were fitted with a function for each of the polyurethane contents. It was found that 
the deformation moduli which is the slope of the stress-strain line (stiffness) increased linearly with the increasing polyurethane content as shown in Fig. 7.

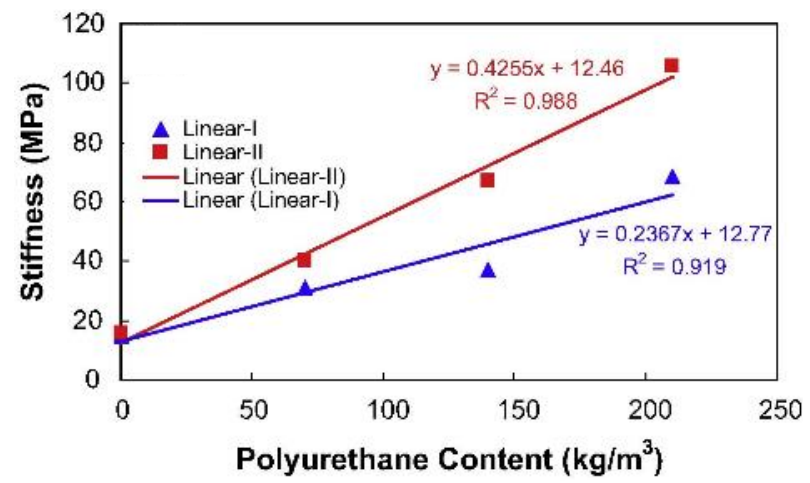

Figure 7. Ballast stiffness vs polyurethane contents under confining stress of $30 \mathrm{kPa}$ [3]

The strength of the mixture was measured, which is here the maximum stress on a stress-strain curve. It was observed that the strength increased linearly with the increasing polyurethane content as shown in Fig. 8.

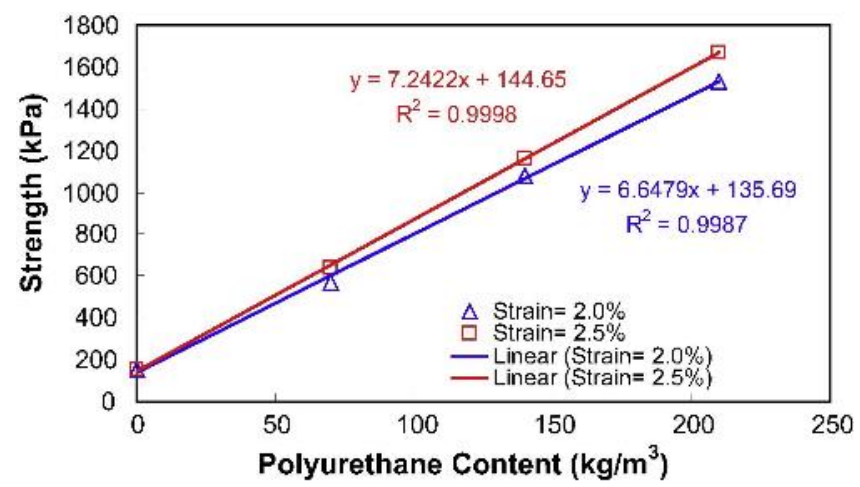

Figure 8. Uniaxial strength of polyurethane-mixed ballast under confining stress of $30 \mathrm{kPa}$ [3]

Gundavaram and Hussaini [12] investigated the effect of adding Elastanpolyurethane stabilizer on the shear strength and breakage of the ballast, then it was compared to the geogrid reinforced ballast by using large-direct shear tests with two 450x450 mm boxes of a $300 \mathrm{~mm}$ depth. The unstabilized ballast was compacted in 3 layers of $100 \mathrm{~mm}$, and in case of geogrid reinforcement, the layer of geogrid was 
placed at the interface of the two boxes (the shear plan). However, for Elastanpolyurethane stabilized ballast, the aggregates with $3 \%$ of the additive by weight of ballast were mixed previously in a concrete mixer for 5 minutes and then compacted with the same method as before and left to cure for 1,3 and 7 days before the test starts. Most of the strength was obtained after 3 days of curing, therefore, all the tests were conducted after that period. The results showed an increase in the secant shear stiffness (shear stress/shear strain) from 5.4 MPa for unreinforced ballast to $5.7 \mathrm{MPa}$ for geogrid reinforced ballast while it reached a max of $10.3 \mathrm{MPa}$ for Elastanstabilized ballast for a normal stress of $60 \mathrm{KPa}$ and shear rate of $3 \mathrm{~mm} / \mathrm{min}$. Furthermore, for the same normal stress and shear rate, a substantial enhancement was reached in the terms of the angle of friction, from $65^{\circ}$ to $75^{\circ}$ after stabilization. Fig. 9 shows the decrease of the angle of friction with the increasing normal stress for the three cases, which can be given as a logarithmic relationship.

Values of stabilization efficiency factor $\mathrm{S}_{\text {ef }}$ (given by the shear strength of stabilized ballast divided by the shear strength of unstabilized ballast) illustrated in Fig. 10 proved the advantage of using Elastan-stabilized ballast with $\mathrm{S}_{\mathrm{ef}}$ between 1.6-1.75. Additionally, in case of Elastan-stabilized ballast, the particles could not be separated to conduct a particle size distribution test, therefore no breakage of ballast was inspected.

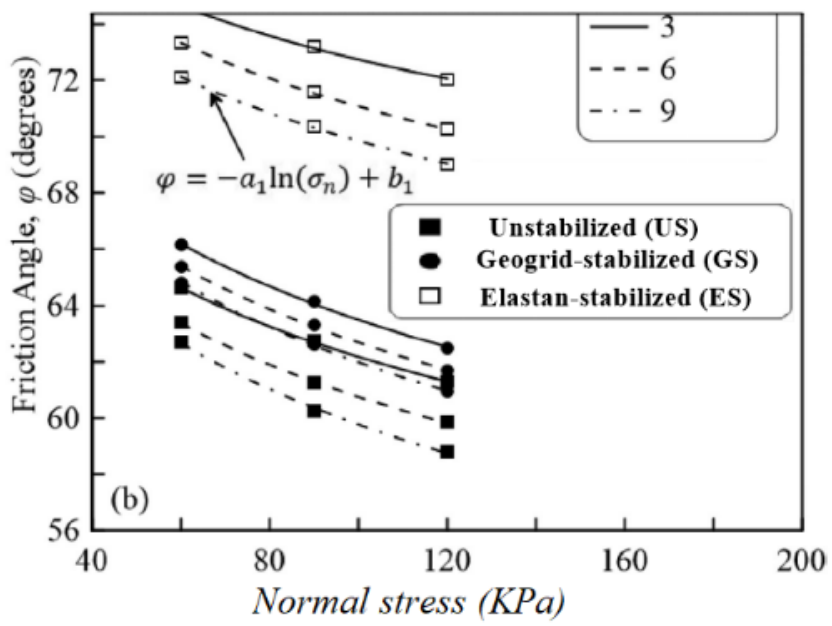

Figure 9. Change of friction angle with normal stress for unstabilized, geogridstabilized and Elastan-stabilized ballast [12] 


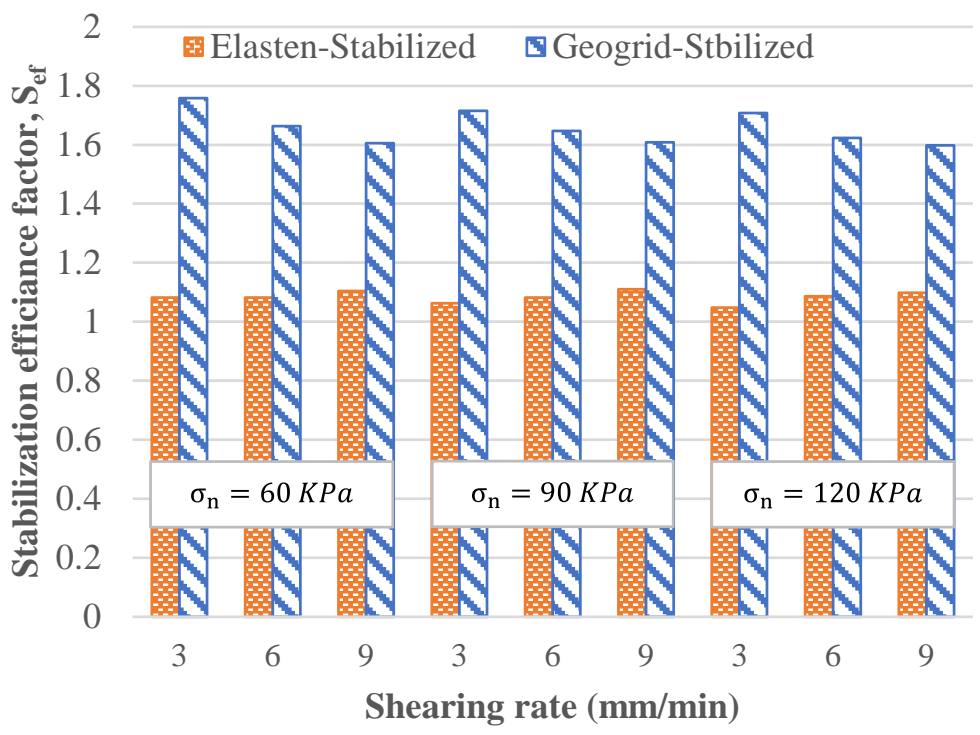

Figure 10.Comparison of stabilization efficiency factor for Elastan and geogridstabilized ballast for different normal stresses and shear rates [12]

The effect of using rubber energy absorbing drainage sheets (READS) beneath the ballast layer to reduce its deformation and degradation (breakage) when subjected to impact loads was examined by T.N. Ngo et al. [4] by conducting large-scale drop hammer impact tests. The tested layers were formed to simulate track conditions as follows: $350 \mathrm{~mm}$ ballast layer placed on a $100 \mathrm{~mm}$ subballast layer separated by the recycled (READ) layer and all resting on a $50 \mathrm{~mm}$ subgrade. 16 tests were performed with soft and concrete subgrade, with and without the rubber mats and with various drop heights which leads to a variation in dynamic stress. After the impact, the ballast layer attains a maximum displacement and then rebounds to its permanent settlement. For a drop height of $150 \mathrm{~mm}$ the maximum and permanent deformations of the ballast without reinforcement reached $84.76 \mathrm{~mm}$ and 74.2. However, adding the rubber mat at the ballast-subballast interface helped diminishing these values to $77.05 \mathrm{~mm}$ and $64.5 \mathrm{~mm}$, respectively. The breakage of the ballast was also measured after the test, and the highest breakage occurred at the top of the specimen where the impact stress is the highest and it decreases as we go deeper. The percentage reduction of ballast breakage $\left(\mathrm{R}_{\mathrm{b}}\right)$ given by:

$$
\mathrm{R}_{b}=\frac{\mathrm{BBI}_{\text {NoReads }}-\mathrm{BBI}_{\text {withreads }}}{\text { BII }_{\text {NoReads }}} \cdot 100,
$$


Where $\mathrm{BBI}$ is the breakage index defined in $[4]$ as " $\mathrm{A} /(\mathrm{A}+\mathrm{B})$, where $\mathrm{A}$ is shift in the PSD curve after the load application, and $\mathrm{B}$ is potential breakage or the area between the arbitrary boundary of maximum breakage and the final PSD curve”. For stiff subgrade, the drop in breakage reached $28 \%$, on the other hand, $\mathrm{R}_{\mathrm{b}}$ was between $10-17 \%$ for soft subgrade. Moreover, a reduction in lateral deformation was obtained after the inclusion of the rubber mats as shown in Fig. 11.

Similar drop hammer tests were conducted by B. Indraratna et al. [13] to study the degradation of ballast reinforced with three different types of biaxial geogrid (various tensile strengths) at different locations under impact loads, in addition to studying the effect of adding under-ballast mat (UBM) or under-sleeper pad (USP) which are $10 \mathrm{~mm}$ thick recycled rubber mats. A variety of tests were performed with two types of subballast, and with either a $150 \mathrm{~mm}$ capping layer of aggregates or a concrete layer of the same thickness. The same process then as the previous test was followed with the inclusion of the rubber mats at the ballast-capping interface in some cases and on top of the ballast layer in other cases. The geogrid was placed at the ballast-capping interface, $10 \mathrm{~cm}$, or $20 \mathrm{~cm}$ above.

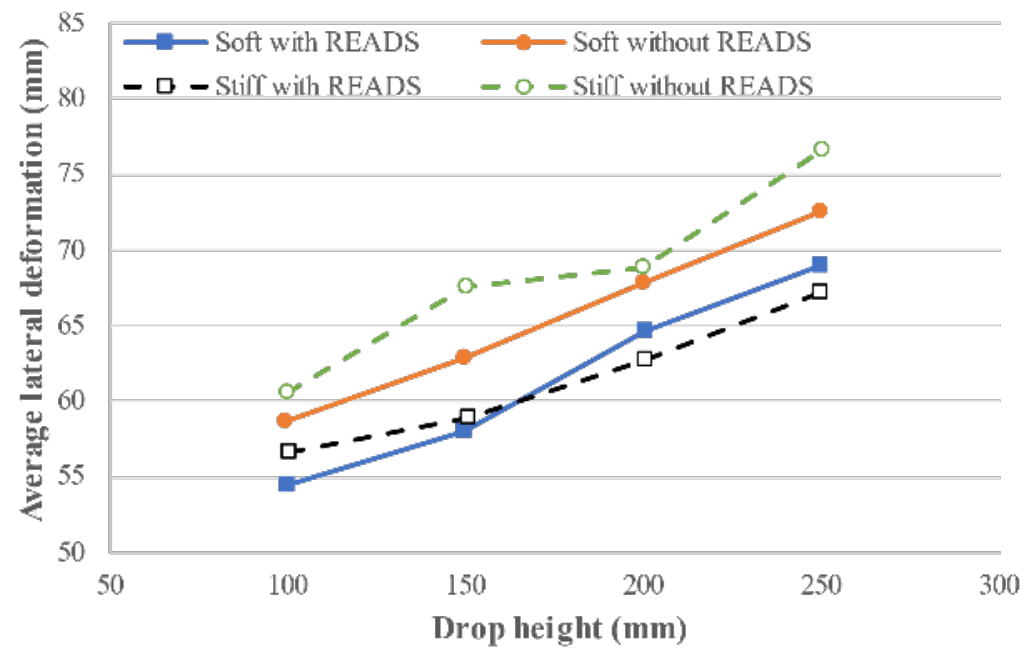

Figure 11.Effect of READS and subgrade type on the final lateral deformation of the ballast [4]

The highest reduction in axial and lateral deformation was achieved when placing the geogrid layer $10 \mathrm{~cm}$ above the ballast-capping interface (up to $18.2 \%$ for axial strain and $21.9 \%$ for lateral strain). Moreover, the inclusion of geogrid diminished the breakage of the ballast by $13.3 \%$ in average of the 3 tests where the geogrid was 
placed in different places, and the highest decrease was noticed when placing the geogrid $10 \mathrm{~cm}$ above the geogrid as (BBI) decreased from 0.1503 to 0.1298 .

The tests also proved that the best combination to enhance the ballast's deformation resistance is to place the geogrid $10 \mathrm{~cm}$ above the ballast-subballast interface and the shock mats at the bottom of the ballast layer, as the axial and lateral strains were reduced by $17.2 \%$ and $26.1 \%$ respectively. On the other hand, when it comes to breakage, the USP placed above the ballast layer reduced breakage by almost 35\% showing a better performance than UBM which showed only a slight improvement. Fig. 12 shows the improvement in deformation resistance when increasing the tensile strength of the geogrid, where the peak tensile strength of GGR1, GGR2, GGR3 is 24.8, 41.7 and $55.3 \mathrm{kN} / \mathrm{m}$ respectively.

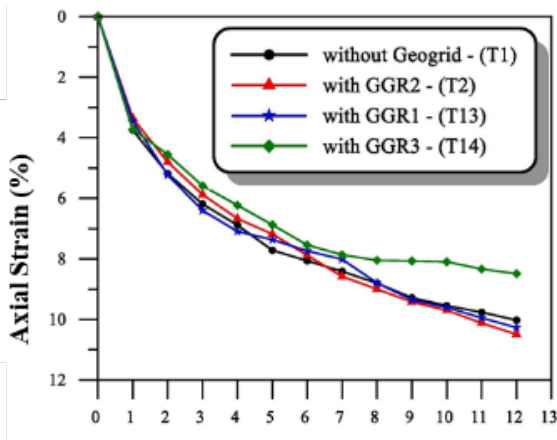

Number of hammer drops (N)

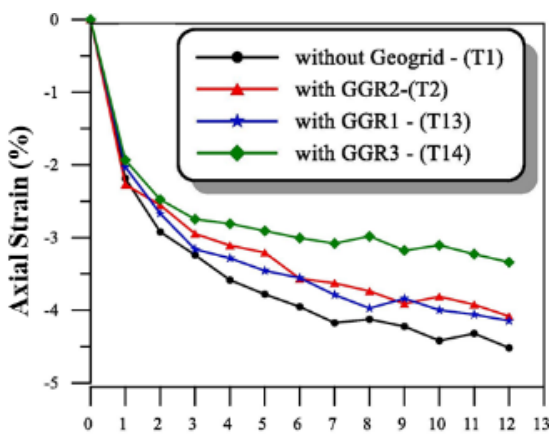

Number of hammer drops (N)

Figure 12. Effect of different geogrids on the performance of ballast under impact loads [13]

D.M. Barbieri et al. [14] tested the benefit of several additives on the mechanical properties and stability of the ballast layer using repeated load triaxial tests. Bitumen Stabilized Ballast (BSB) contained 3\% of bitumen by weight and were mixed in a steel bowl. On the other hand, Polyurethane Stabilised Ballast (PSB), Lignosulfonate Stabilised Ballast (LSB), and Organosilane Stabilised Ballast (OSB) contained $1.5 \%, 0.65 \%$ and $1.5 \%$ of polyurethane, lignosulfonate and organosilane binders by weight, respectively, by adding the binder and mixing in plastic bags, then each specimen was compacted and cured for a certain time as shown in Table 1. 
Table 1. Summary of the tested samples by D.M. Barbieri et al [14]

\begin{tabular}{|c|c|c|c|c|c|c|}
\hline \multirow[b]{2}{*}{ Additive } & \multirow[b]{2}{*}{ Code } & \multirow{2}{*}{$\begin{array}{c}\text { Additive } \\
\text { content } \\
\text { (weight \%) }\end{array}$} & \multicolumn{2}{|c|}{ Curing } & \multirow{2}{*}{$\begin{array}{c}\text { Bulk } \\
\text { density } \\
\left(t / m^{3}\right)\end{array}$} & \multirow{2}{*}{\begin{tabular}{|c} 
Price \\
estimate \\
$($ EUR/kg)
\end{tabular}} \\
\hline & & & $\begin{array}{l}\text { Time } \\
\text { (day) }\end{array}$ & $\begin{array}{c}\text { Temperature } \\
\left(\mathrm{c}^{0}\right)\end{array}$ & & \\
\hline Untreated & UGM & - & & & 1.68 & - \\
\hline $\begin{array}{c}\text { Bitumen } \\
70 / 100\end{array}$ & BSB1 & 3.0 & 2 & 22 & 1.73 & 0.4 \\
\hline $\begin{array}{l}\text { Bitumen } \\
160 / 220\end{array}$ & BSB2 & 3.0 & 2 & 22 & 1.73 & 0.4 \\
\hline organosilane & OSB & 1.5 & 7 & 22 & 1.73 & 9 \\
\hline lignosulfonate & LSB & 0.7 & $2+5$ & $50+22$ & 1.7 & 0.6 \\
\hline polyurethane & PSB & 1.5 & 2 & 22 & 1.69 & 4.5 \\
\hline
\end{tabular}

The diameter of the specimens was $150 \mathrm{~mm}$ with heights varying between 176$188 \mathrm{~mm}$. Five sequences of different confining stresses and increasing intensities of sinusoidal dynamic vertical stresses up to $600 \mathrm{KPa}$ with 6 loading steps were applied to the specimen. the resilient modulus for a certain sequence here was given by:

$$
\mathrm{M}_{R}=\frac{\Delta \sigma_{d}^{d y n}}{\varepsilon_{a}^{e l}}
$$

Where, $\Delta \sigma_{d}^{d y n}$ is the dynamic deviatoric stress and $\varepsilon_{a}^{e l}$ is the axial resilient strain.

Fig. 13 shows the calculated resilient moduli plotted based on Hicks \& Monismith equation given by:

$$
\mathrm{M}_{R}=\mathrm{K}_{1 . H M} \sigma_{a}\left(\frac{\theta}{\sigma_{a}}\right)^{\mathrm{K}_{2 . H M}}
$$

where " $\sigma_{a}$ is a reference pressure $(100 \mathrm{kPa})$ and $\mathrm{K}_{1 . H M}, \mathrm{~K}_{2 . H M}$ are regression parameters" [14], and $\theta=\sigma_{1}+\sigma_{2}+\sigma_{3}$. The resilient modulus was significantly increased for all the additives except for polyurethane. As an example, the values of the resilient moduli for UGM, OSB, BSB2, BSB1, and LSB are $460 \mathrm{MPa}$, $756 \mathrm{MPa}$ $1612 \mathrm{MPa}, 1935 \mathrm{MPa}$, and $2335 \mathrm{MPa}$, respectively for $\theta=200 \mathrm{kPa}$. This shows that the lignosulfonate was the most effective. Furthermore, the vertical displacements were compared for the five loading sequences. The comparison indicated a considerable decrease in the permanent deformations after using the additives especially for PSB and LSB. The values of permeant vertical deformations for the first sequence and for a vertical stress to confining stress ratio of 5 were 5.55 , $1.40,2.90,4.10,0.65,0.50$ for UGM, BSB1, BSB2, OSB, LSB and PSB, respectively. 


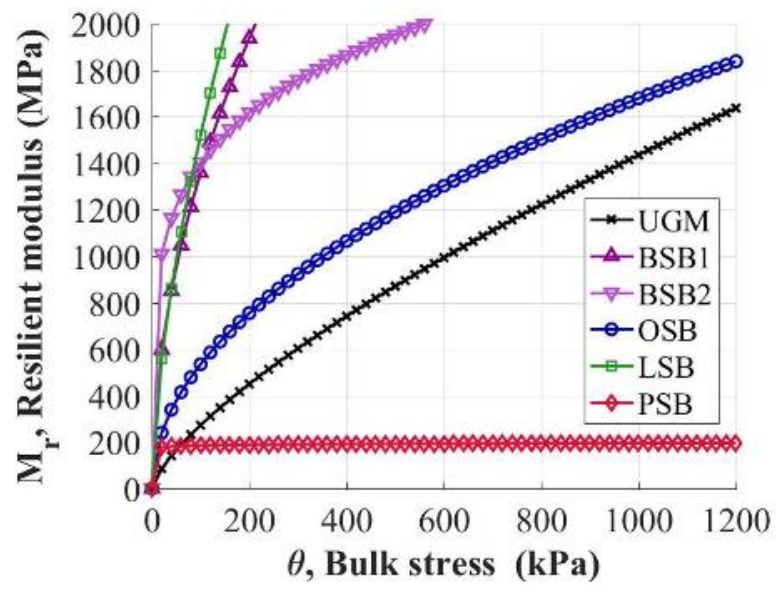

Figure 13. Resilient moduli vs Bulk stress of tested samples according to Hicks \& Monismith model [14]

G. Jing et al. [15] presented three new methods of bonding to strengthen ballast with the use polyurethane, for the purpose of investigating the lateral resistance of the ballast, they conducted single sleeper pull-out test (SSPT) to assess the lateral resistance of the strengthened ballast layer. In these new methods only 4 regions of the ballast are reinforced which are considered the most vulnerable regions, two regions close to the center of the sleeper and the other two are at the sleeper ends as can be seen in Fig. 14. In method (E), the parts of the shoulder ballast close to the two sleeper ends should be bonded. On the other hand, in method (C) it is required for the crib ballast near the sleeper center to be bonded. For the last method (B), both the ballast near the sleeper end and center shall be bonded. G. Jing et al. [15] also studied two bonding depths of $200 \mathrm{~mm}$ and $300 \mathrm{~mm}$.

For the test, the ballast layer was compacted in 4 layers to a thickness of $350 \mathrm{~mm}$ with a width of $3600 \mathrm{~mm}$ for a $12 \mathrm{~m}$ long track. Type IIIc pre-stressed concrete sleepers were used on the top of the ballast. A spraying mechanism was employed to apply the polyurethane to the top surface of the ballast. A lateral force was applied to the sleepers and the lateral resistance and deformations are measured. The test results show a substantial improvement in the lateral resistance after reinforcement for the three bonding methods, and the improvement is higher for a bonding depth of $300 \mathrm{~mm}$. A comparison between the enhancement that the different methods provide at a sleeper displacement of $2 \mathrm{~mm}$ are shown in Fig. 15, where the numbers above the bars indicate the difference between the bonding method and tests with no binders. 


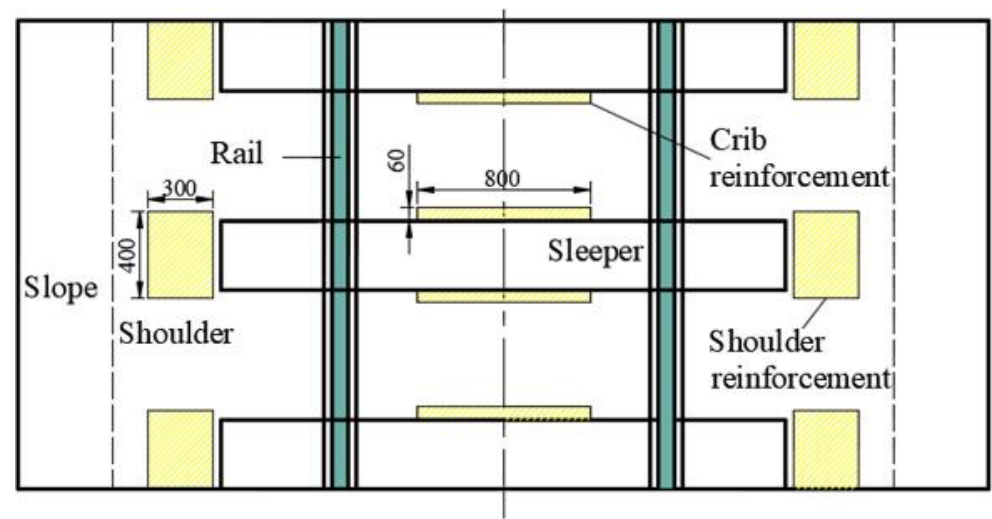

Figure 14. Sketch of the new bonding schemes for strengthening the ballast layer using polyurethane (the target regions are in yellow) [15]

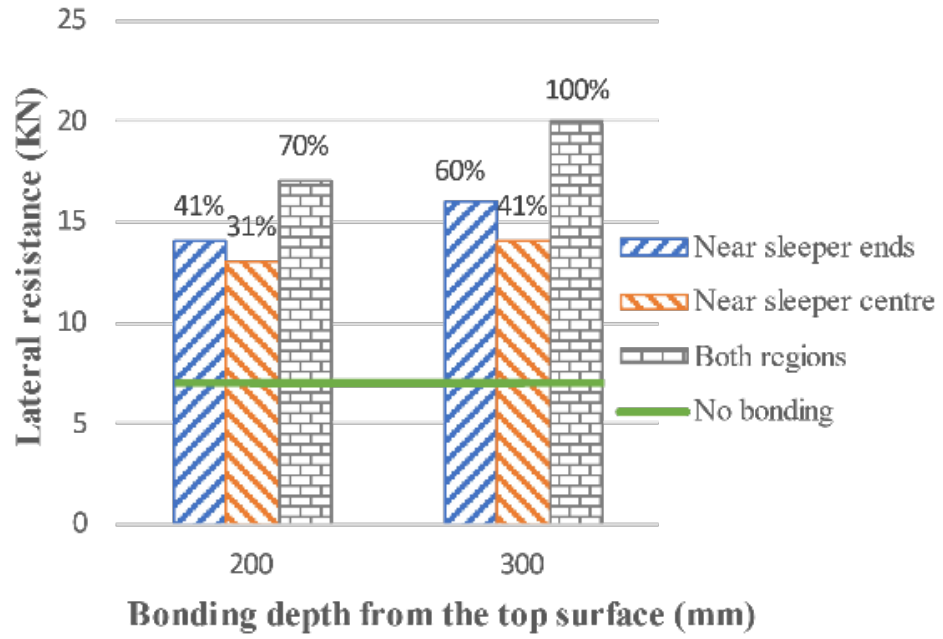

Figure 15. Lateral resistance forces of ballast at $d=2 \mathrm{~mm}$ in various tests and their differences [15]

\section{Conclusions}

The review presented in this paper indicates substantial benefits of reinforcing the ballast layer to decrease the permanent deformations and improve the railway 
stability in addition to decreasing the cost and frequency of maintenance work. This enhancement is attributed to the geogrid-ballast interlocking which increases the shear strength and the effective confining pressure of the ballast which detains and restricts the displacement and rotation of the ballast. As a result, it is more beneficial to install the geogrid in the ballast layer (about $10 \mathrm{~cm}$ above the bottom) rather than underneath it, in order to gain more contact between the two elements.

Studies have proven that using square shaped geogrid caused a better improvement in the ballast layer shear strength than using triangle shaped geogrid, due to the higher effective aperture of such type of geogrid which is more compatible with the particle size distribution of the aggregates that comprise the ballast, and it was also found that geogrid with higher tensile strength can further improve the deformation resistance as well as adding another layer of geogrid. However, it was found that a better performance can be achieved with the use of some types of binders to stabilize the ballast because of the strong bonding between all the ballast particles of different sizes due to the additives' coating, rather than a few particles of specific size gets interlocked in the geogrid apertures. Nevertheless, a disadvantage accompanies this feature by making the maintenance a more difficult and complicated process in addition to the extended construction cost and time, while it is easier to perform the maintenance work of the railway in case of geogrid reinforced ballast. Such factors should be taken into consideration depending on the country's resources and circumstances before choosing the reinforcement method. Furthermore, bitumen, lignosulfonate and polyurethane are the best binders with a slight advantage for lignosulfonate considering the price difference. It can be also mentioned that more viscous binders attain a major increase in stiffness.

The new scheme of additives distribution reduces the height of the ballast shoulder and the dosage of the polyurethane considerably as the percentages of the areas occupied by the reinforced ballast in the three new methods of bonding are only $18.1 \%, 7.2 \%$, and $25.3 \%$ of the total area, respectively. Thus, the new methods of bonding are more cost effective in both the dosage of polyurethane material, and the ballast, considering the high cost of the polyurethane that could reach 150.000 Euros per kilometer, which limits its application in ballast reinforcement.

In case of impact dynamic loading, it was observed to be very beneficial to use rubber mats at the ballast-subballast interface along with the usage of a geogrid layer to attenuate the loads and absorb the energy resulted from such types of loads, leading to a decrease in the vertical and lateral displacement.

\section{References}

[1] B. Eller, S. Fischer, Tutorial on the emergence of local substructure failures in the railway track structure and their renewal with existing and new 
methodologies. Acta Technica Jaurinensis 14 (1) (2021) pp. 80-103, 2021. doi: https ://doi.org/10.14513/actatechjaur. 00565

[2] R.M. Koerner, Designing with Geosynthetics, 6th Edition, Vol. 1, Xlibris, USA, 2012.

[3] S.H. Lee, S.J. Lee et al., An experimental study on the characteristics of polyurethane-mixed coarse aggregates by large-scale triaxial test. Construction and Building Materials 145 (2017) pp. 117-125. doi: https ://doi .org/10.1016/j . conbuildmat . 2017. 03.107

[4] N.T. Ngo, B. Indraratna, C. Rujikiatkamjorn, Improved performance of ballasted tracks under impact loading by recycled rubber mats. Transportation Geotechnics 20 (2019) 100239. doi: https://doi.org/10.1016/j.trgeo.2019.04.002

[5] E. Juhász, S. Fischer, Railroad Ballast Particle Breakage with Unique Laboratory Test Method. Acta Technica Jaurinensis 12 (1) (2019) pp. 26-54. doi: https ://doi.org/10.14513/actatechjaur.v12.n1.489

[6] F. Horvát, S. Fischer, Z. Major, Evaluation of railway track geometry stabilisation effect of geogrid layers under ballast on the basis of laboratory multi-level shear box tests. Acta Technica Jauriensis 6 (2) (2013) pp. 21-44.

[7] M. Esmaeili, J.A. Zakeri, Laboratory and field investigation of the effect of geogrid-reinforced ballast on railway track lateral resistance. Geotextiles and Geomembranes 45 (2017) pp. 23-33.

doi: https://doi.org/10.1016/j.geotexmem.2016.11.003

[8] K. Sweta. S.K.K. Hussaini, Behavior evaluation of geogrid-reinforced ballastsubballast interface under shear condition. Geotextiles and Geomembranes 47 (1) (2019) pp. 23-31.

doi: https ://doi.org/10.1016/j.geotexmem.2018.09.002

[9] K. Sweta. S.K.K. Hussaini, Effect of geogrid on deformation response and resilient modulus of railroad ballast under cyclic loading. Construction and Building Materials 264 (2020), 120690.

doi: https ://doi .org/10.1016/j . conbuildmat . 2020.120690 
[10] J. Sadeghi, A.R.T. Kian et al., Effectiveness of geogrid reinforcement in improvement of mechanical behavior of sand-contaminated ballast. Geotextiles and Geomembranes 48 (6) (2020) pp. 768-779. doi: https://doi.org/10.1016/j.geotexmem.2020.05.007

[11] R.P. Singh, S. Nimbalkard et al., Field assessment of railway ballast degradation and mitigation using geotextile. Geotextiles and Geomembranes 48 (3) (2020) pp. 275-283.

doi: https ://doi.org/10.1016/j .geotexmem. 2019.11.013

[12] D. Gundavaram, S.K.K. Hussaini, Performance evaluation of polyurethanestabilized railroad ballast under direct shear conditions. Construction and Building Materials 255 (2020) 119304. doi: https ://doi .org/10.1016/j . conbuildmat . 2020.119304

[13] B. Indraratna, N.T. Ngo et al., Laboratory examination of ballast deformation and degradation under impact loads with synthetic inclusions. Transportation Geotechnics 25 (2020) 100406. doi: https://doi.org/10.1016/j.trgeo.2020.100406

[14] D.M. Barbieri, M. Tangerås et al., Railway ballast stabilising agents: Comparison of mechanical properties. Construction and Building Materials 252 (2020) 119041. doi: https ://doi .org/10.1016/j . conbuildmat . 2020.119041

[15] G. Jing, X. Zhang, W. Jia, Lateral resistance of polyurethane-reinforced ballast with the application of new bonding schemes: Laboratory tests and discrete element simulations. Construction and Building Materials 221 (2019) pp. 627-636. doi: https ://doi .org/10.1016/j . conbuildmat . 2019.06.114

[16] Standard Test Method for Direct Shear Test of Soils under, ASTM D3080 (2003).

[17] Standard Test Method for Resistance to Degradation of Small-Size Coarse Aggregate by Abrasion and Impact in the Los Angeles Machine, ASTM C131 / C131M-20 (2020). 